\title{
Children and adolescent solid
}

\section{tumours and high-intensity end-of- life care: what can be done to reduce acute care admissions?}

\author{
Marta Giorgia Podda (D) , ${ }^{1}$ Elisabetta Schiavello, ${ }^{1}$ Carlo Alfredo Clerici, ${ }^{1,2}$ \\ Roberto Luksch, ${ }^{1}$ Monica Terenziani, ${ }^{1}$ Andrea Ferrari, ${ }^{1}$ \\ Michela Casanova, ${ }^{1}$ Filippo Spreafico, ${ }^{1}$ Cristina Meazza, ${ }^{1}$ \\ Veronica Biassoni, ${ }^{1}$ Stefano Chiaravalli, ${ }^{1}$ Nadia Puma, ${ }^{1}$ \\ Luca Bergamaschi, ${ }^{1}$ Giovanna Gattuso, ${ }^{1}$ Giovanna Sironi, ${ }^{1}$ Olga Nigro, ${ }^{1}$ \\ Maura Massimino ${ }^{1}$
}

${ }^{1}$ Pediatric Oncology Unit, Fondazione IRCCS Istituto Nazionale dei Tumori, Milano, Italy

${ }^{2}$ Psychology Unit, Fondazione IRCCS Istituto Nazionale dei Tumori, Milano, Lombardia, Italy

\section{Correspondence to} Dr Marta Giorgia Podda, Pediatric Oncology Unit, Fondazione IRCCS Istituto Nazionale dei Tumori, Milano, Italy;

marta.podda@istitutotumori.mi.it

Received 5 March 2021 Accepted 17 August 2021

\section{Check for updates}

(c) Author(s) (or their employer(s)) 2021. No commercial re-use. See rights and permissions. Published by BMJ.

\footnotetext{
To cite: Podda MG, Schiavello E, Clerici CA, et al. BMJ Supportive \& Palliative Care Epub ahead of print: [please include Day Month Year]. doi:10.1136/ bmjspcare-2021-003031
}

\section{ABSTRACT}

Despite improvements in survival, cancer remains the leading cause of non-accidental death in children and adolescents, who risk receiving high-intensity end-of-life (HI-EOL) care.

Objective To analyse treatments for relapses (particularly in the last weeks of life), assess their impact on the EOL, identify patients most likely to receive $\mathrm{HI}-\mathrm{EOL}$ care and examine whether palliative care services can contain the intensity of EOL care.

Methods This retrospective study involved patients treated at the paediatric oncology unit of the Istituto Nazionale Tumori in Milan who died between 2018 and 2020. The primary outcome was HI-EOL care, defined as: $\geq 1$ session of intravenous chemotherapy $<14$ days before death; $\geq 1$ hospitalisation in intensive care in the last 30 days of life and $\geq 1$ emergency room admission in the last 30 days of life.

Results The study concerned 68 patients, and 17 had HI-EOL care. Patients given specific in-hospital treatments in the last 14 days of their life more frequently died in hospital. Those given aggressive EOL care were less likely to die at home or in the hospice. Patients with central nervous system (CNS) tumours were more likely to have treatments requiring hospitalisation, and to receive $\mathrm{HI}$-EOL care

Conclusion These results underscore the importance of considering specific treatments at the EOL with caution. Treatments should be administered at home whenever possible. The early activation of palliative care, especially for fragile and complicated patients like those with CNS cancers, could help families cope with the many problems they face.

\section{Key messages}

What was already known?

- Children with cancer experience a heavy burden of symptoms at the end of life (EOL).

- Patients who receive high-intensity EOL (HI-EOL) care are more likely to die in acute care wards.

What are the new findings?

- Patients with central nervous system tumours receive HI-EOL care more often than those with other tumours.

- Patients given aggressive EOL care were less likely to die at home or in the hospice.

What is their significance?

- The pros and cons of palliative treatment must be carefully weighed, especially in patients with brain tumours.

\section{INTRODUCTION}

Although the outcome for children and adolescents with cancer has improved significantly in the last decade, between 2000 and 2008, there were a mean 244 cancer-related deaths a year involving patients under 20 years old in Italy, corresponding to an annual rate of 3.5 per $100000 .^{1}$

Even with advances in treatment and improved survival rates, more than one in four children with central nervous system (CNS) tumours will succumb to their disease. ${ }^{2}$ Children dying from CNS tumours have unique end-of-life (EOL) symptoms, including communication difficulties, dysphagia impairing the 
administration of medication, limb paralysis, headache, seizures and cognitive and behavioural changes. ${ }^{3}$

The use of cancer-directed therapies even when there is no realistic chance of cure is becoming increasingly common, mainly due to patients' accrual into early-phase drug trials. Many parents report afterwards, however, that their children suffered as a result of their agreeing to such treatments, and they would advise other families against doing so. ${ }^{3}$

Several studies have documented that many children with cancer experience a heavy burden of symptoms at the EOL, due partly to the high-intensity medical care they receive. ${ }^{4-7}$

Oncologists are sometimes reluctant to activate early palliative care, partly because of their own emotional involvement and awareness of the generally good prognosis of paediatric patients with cancer, and partly because they fear depriving parents of their last hopes. ${ }^{8}$ Advances in cancer treatments have also led to rising numbers of phase I trials postponing the parents' and oncologists' acceptance of a patient's incurability. In some cases, a refusal to accept a poor or uncertain prognosis (when it is difficult to estimate a patient's life expectancy) prompts oncologists to propose oncological treatments-even for palliative purposes-that can result in an excessive hospitalisation of patients near the end of their life.

Much importance has been attributed to the early activation of palliative care also to limit HI-EOL) treatment. $^{6} 79$ The availability of palliative care services depends on a patient's area of residence, as it varies widely in different parts of Italy, and some areas lack sufficient resources to provide simultaneous care. In the Milan area, the service has been delivered by a non-profit associationunder a partnership with doctors specialising in paediatric palliative care (PPC) since $2015 .{ }^{10}$ Patients who live elsewhere may be able to access the palliative care available for adults, which is adapted to paediatric patients (where possible) by an ad hoc team.

\section{Aim}

We analysed a cohort of patients treated at a paediatric oncology ward, focusing on: (1) treatments they received after a first relapse and in the last weeks of life (type and place of administration) and (2) the impact these treatments may have had on the EOL. Secondary objectives were to ascertain which types of patient were most likely to receive HI-EOL care, and whether activating palliative care service would have affected its intensity.

\section{METHODS}

Patients treated at the paediatric oncology unit of IRCCS Istituto Nazionale dei Tumori (Milan, Italy) for a solid cancer and who died between January 2018 and January 2020 were all retrieved and analysed from the department's database. This is a retrospective chart review. We excluded patients only coming to our hospital to be enrolled in phase I/II trials with new drugs because they were only followed by our team for short periods of time, and decisions regarding their subsequent treatments and when to refer them to palliative care were not shared with us. All other patients treated in the years 2018-2020 were retrieved and analysed.

There are some adult patients in the sample either because they had been diagnosed with cancers of childhood and were consequently treated at our department, or because their disease had first been diagnosed in paediatric age and then relapsed in adulthood. The primary outcome was HI-EOL care, defined as the experience of at least once of the following: (1) $\geq 1$ session of in-hospital intravenous chemotherapy or radiotherapy $<14$ days before death; $(2) \geq 1$ hospitalisation in an intensive care unit (ICU) in the last 30 days of life and (3) $\geq 1$ emergency room admission in the last 30 days of life. As there are no defined paediatric criteria of HI-EOL, we used indicators developed from $^{79-11}$ previous population-based research ${ }^{4} 91213$ on children and adults. We added as a further indicator the administration of radiotherapy $<14$ days before death as about a half of patients were patients with CNS tumours and this treatment often requires a patient's admission to hospital—especially for patients undergoing reirradiation.

As a whole, we analysed the treatments proposed after a first relapse (chemotherapy or radiotherapy, surgery), the timing and modality of specialised palliative care team involvement, the place of death, emergency room and ICU admissions during the last month of life, and the time elapsing between the last specific treatment and death. Palliative care involvement is usually noted in the medical chart. Preschool age was defined as up to 6 years old. Teenager and young adults were patients $>15$ years old. The $\chi^{2}$ test was used to compare different groups. Significance was set at $\mathrm{p}<0.05$

\section{RESULTS}

Overall 90 patients died during the study. Twenty-two of the 90 patients were excluded from the analysis because they came to our centre only to take part in an early-phase drugs trial. Mean age at diagnosis was 9 years (1-33), at death 13 (2-35). Twenty-nine of 68 patients were female. After their first relapse the median number of chemotherapy lines administered was 1 (range 0-7), and for radiotherapy (for primary tumours or recurrences), it was also 1 (0-6). The patients surviving the longest were those with sarcoma, who were also the patients receiving the largest number of treatment lines (see table 1). All patient died for disease progression.

Forty-three of 68 patients lived in Lombardy region (26 of them in and around the city of Milan, where our hospital is located), and 25/68 moved from other 
Table 1 Characteristics of cohort $(n=68)$ : diagnosis, treatment and site of death, lines of therapy according to diagnosis after relapse

\begin{tabular}{|c|c|c|c|c|c|c|c|c|c|c|}
\hline \multirow[b]{2}{*}{ Cancer type } & \multirow[b]{2}{*}{ Patients, N } & \multirow[b]{2}{*}{ Patients \% } & \multirow[b]{2}{*}{ PCT } & \multicolumn{2}{|c|}{ Place of death } & \multirow{2}{*}{$\begin{array}{l}\text { CT lines Range } \\
(0-7) \\
\begin{array}{l}\text { Mean/ } \\
\text { median }\end{array}\end{array}$} & \multirow{2}{*}{$\begin{array}{l}\text { RT lines } \\
\text { Range (0-6) } \\
\begin{array}{l}\text { Mean/ } \\
\text { median }\end{array}\end{array}$} & \multirow{2}{*}{$\begin{array}{l}\mathrm{S} \\
\text { Range (0-5) } \\
\begin{array}{l}\text { Mean/ } \\
\text { median }\end{array}\end{array}$} & \multirow{2}{*}{$\begin{array}{l}\text { Months from } \\
\text { diagnosis to } \\
\text { relapse }\end{array}$} & \multirow{2}{*}{$\begin{array}{l}\text { Months from } \\
\text { relapse to } \\
\text { death }\end{array}$} \\
\hline & & & & $\begin{array}{l}\text { Home/ } \\
\text { hospice }\end{array}$ & Other & & & & & \\
\hline CNS & 35 & 51 & 26 & 22 & 13 & $1 / 1$ & $0.8 / 1$ & $0.3 / 0.8$ & $11 / 9$ & $11 / 6$ \\
\hline Sarcoma & 23 & 34 & 19 & 17 & 6 & $2 / 2$ & $0.7 / 0$ & $0.4 / 0$ & $16 / 12$ & $13 / 5$ \\
\hline \multicolumn{11}{|c|}{ OS 6, Ewing 6, STS 11} \\
\hline NBL & 6 & 9 & 6 & 5 & 1 & $3.1 / 2.5$ & $0.8 / 1$ & $0.1 / 0$ & $34 / 16.5$ & $17 / 17$ \\
\hline Other & 4 & 6 & 4 & 3 & 1 & $4 / 3.5$ & $0.2 / 0$ & $0.2 / 0$ & $9.2 / 7$ & $18 / 14.5$ \\
\hline
\end{tabular}

CNS, central nervous system; NBL, neuroblastoma; OS, osteosarcoma; PCT, palliative care team; S, surgery; STS, soft tissue sarcoma.

Italian regions. Thirty-one of the 68 patients died at home, 16 in a hospice, 9 in our paediatric oncology ward, 11 in other general hospital wards and 2 in ICUs outside Lombardy. The probability of dying at home was significantly associated with the patient's family living not in Lombardy, but in Milan or its hinterland $(\mathrm{p}=0.0047)$. Patients with CNS tumours died more frequently in hospital (65\% vs $45 \%$ ), though the difference was not statistically significant. Six of the nine patients who died in our ward had CNS tumours (see table 2).

For $62 / 68$ patients, the duration of the chemotherapies and radiotherapies administrated was known, while for six patients on oral treatments the time elapsing between stopping their therapy and their death was not recorded. For the former 62 patients, the median time elapsing between the last dose of chemotherapy (either per os or intravenous) and death was 27 days. In the last 2 weeks of life, 21/62 patients (33\%) received treatments, which required hospitalisation in 9 cases (14.5\%), 7 patients with CNS tumours and 2 with sarcomas. These treatments involved radiotherapy and intravenous chemotherapy in five and four patients, respectively. Patients given specific treatments in hospital in the last 14 days of their life were more likely to die in the paediatric oncology ward $(\mathrm{p}=0.0001)$.

When we examined which patients received HI-EOL care, data were available for 65 of the 68 patients, and 17 of them (26\%) met at least one of the three criteria to define HI-EOL. Seven admission to emergency department in the last month of life $(10 \%) ; 5$ admission to ICU in the last month of life $(7 \%)$ and 10 patient (14\%) received treatment in hospital last 14 days (intravenous chemotherapy or radiotherapy).

A palliative care programme had been in place for $55 / 68$ patients $(80 \%)$ (ever since their diagnosis in three cases). Twenty-three out of 55 patients were in the care of a PPC team, and is known the exactly date of involvement of the service, as described in another paper. ${ }^{10}$ Other patients received palliative care delivered by teams for adults, which was adapted case by case. Twenty-one of 23 patients in the care of a paediatric palliative team had more than 1 month between first consultation and death

Patients on a palliative care programme were less likely to receive HI-EOL care $(\mathrm{p}=0.0001)$.

Patients with CNS tumours $(\mathrm{n}=32)$ were more likely to receive treatments that required hospitalisation during the last 14 days of their life, though this finding

\begin{tabular}{|c|c|c|c|c|c|c|c|c|c|}
\hline & & & \multicolumn{7}{|c|}{ Place of death } \\
\hline & & & Home & Hospice & POU & Other hospital & Home+hospice & Hospital & $P$ value \\
\hline \multicolumn{10}{|l|}{ Diagnosis } \\
\hline $\mathrm{CNS}=35$ & & & 14 & 8 & 6 & 7 & 22 & 13 & ns \\
\hline Other tumours $=33$ & & & 17 & 8 & 3 & 5 & 25 & 8 & \\
\hline \multicolumn{10}{|l|}{$\begin{array}{l}\text { HI-EOL (data on } 65 \\
\text { points) }\end{array}$} \\
\hline Yes $=17$ & & & 2 & 4 & 5 & 6 & 6 & 11 & 0.0009 \\
\hline $\mathrm{No}=48$ & & & 27 & 11 & 4 & 6 & 38 & 10 & \\
\hline \multicolumn{10}{|l|}{$U n=3$} \\
\hline $\begin{array}{l}\text { Treatment in hospital } \\
\text { last } 14 \text { days (data on } 68 \\
\text { points) }\end{array}$ & $\begin{array}{l}\text { Death in } \\
\text { oncology ward }\end{array}$ & & & & & & & & \\
\hline Yes $=9$ & 5 (other=4) & $P=0.0001$ & 1 & 2 & 6 & 0 & 4 & 5 & ns \\
\hline $\mathrm{No}=59$ & 4 (other=55) & & 30 & 13 & 4 & 12 & 43 & 16 & \\
\hline
\end{tabular}

CNS, central nervous system; HI-EOL, high-intensity end of life; ns, not significant; POU, paediatric oncology unit; un, unknown. 
was not statistically significant $(\mathrm{p}=0.06)$. Patients with CNS tumours significantly received HI-EOL care more often than those with other solid tumours $(\mathrm{p}=0.0188)$.

Patients receiving aggressive EOL care $(n=17)$ more often died in ordinary hospital wards than at home or in a hospice, and this difference was statistically significant $(\mathrm{p}=0.0009)$.

When we grouped our series by age at time of death, first distinguishing between preschool-aged children $(n=16)$ and older patients $(n=52)$, we found that $10 / 16$ patients < 6 years old $(60 \%)$ died at home, as opposed to $21 / 52(40 \%)$ in the older group $(p=0.36)$. When these two age groups were compared in terms of deaths in the hospice, only $1 / 16$ younger patients $(6 \%)$ died in the hospice, as opposed to $15 / 52$ older patients $(28 \%)(p=0.12)$. When we grouped and compared the patients by age $>15$ as opposed to $<15$ years, no significant differences emerged regarding the place of death.

\section{DISCUSSION}

EOL management in paediatric oncology always confronts doctors with complex situations because every family, and every single patient, depending on their age and type of cancer, have their own particular features.

This is a mono-institutional study involving 68 patients which shows that $26 \%$ of patients receive HI-EOL care during the last 30 days of life. This is the first Italian study regarding the intensity of EOL care in paediatric patients with solid cancer.

Approximately 40 patients treated at our centre die each year. ${ }^{10}{ }^{14}$ Patients with CNS tumours and sarcomas made up the majority of our series (85\%). Patients with CNS tumours are complex cases due to the multiple impairments ${ }^{1516}$ their disease may cause. Their symptoms can be extremely disabling and difficult for families to handle, for example, swallowing difficulties, communication problems, paralysis with a consequent need for aids like wheelchairs, nasogastric tubes or gastrostomy. These patients also often have complications like hydrocephalus that demand intervention at specialised centres (neurosurgery departments).

The probability of dying at home was significantly associated with the patient's family living in Milan or its hinterland and this is for the presence of a partnership with a paediatric PPC team. ${ }^{10}$ Access to palliative care in Lombardy is really different: there are some area well served, some teams, although dedicated to adults, are able to customised their services on paediatric patients. In other area, there is no availability for children.

Drawing a comparison with our previous data, ${ }^{14}$ we confirmed a trend towards fewer paediatric patients dying in hospital wards for acute patients (this applied to $34 \%$ of a series studied in 2006 , and to $16 \%$ of the present one) and an increase in deaths in dedicated structures $(8.5 \%$ vs $23.5 \%)$. The past decade has seen a general tendency to optimise supportive care throughout the course of a disease, including concurrent palliative care services. ${ }^{10}$

Comparing the place of death for our patients with other published case series proved quite difficult. Other countries have different healthcare systems, and the availability of territorial palliative care varies, not only within a given country, but even within the same region. ${ }^{17}$ That said a recent paper shows that in Ile de France (IDF) the hospital was the most frequent place of death (75\% of patients). ${ }^{17}$ This proportion has remained stable since 2002 in IDF. ${ }^{18}$ Conversely, in the Lyon area, the rate of home death is higher $(65 \%)$ in relation to a very dedicated and mobile PPC team, a single tertiary centre and a lower population density. ${ }^{19} 20$ In England, hospitals and home were the main EOL setting for children and young adult. The home death rate $(\sim 40 \%)$ barely changed in the past two decades, and deaths in hospital remained the most common but slightly shifted towards hospices. ${ }^{21}$ In USA, a paper of St.Jude Hospital reported home death in 53\%, hospital death in 38\% (43\% in ICU) and hospice $3.4 \% .^{22}$

There may also be cultural factors that have a bearing on EOL management choices.There are no recent published data regarding the place of death on the entire Italian territory. Data of 2006-2007 describe $40 \%$ of children's suffering from malignant neoplastic diseases die at home: the figure is $60 \%$ for southern Italy and $10 \%-15 \%$ in the north; patients in southern Italy often stay at home because of shortcomings at the local hospital or hospice. ${ }^{23-25}$

Patients who receive aggressive EOL care are more likely to die in acute care wards (or paediatric oncology wards, or paediatric wards closer to home, or ICUs), possibly because of the adverse effects of treatments. ${ }^{12}$ The patients most likely to receive HI-EOL care are understandably those with CNS cancer, as their management is extremely complex from early on in the course of their disease, largely for the reasons mentioned above. Another reason lies in the benefits of radiotherapy for palliation for CNS tumours $^{26-28}$ which can only be delivered in hospital (patients frequently need to be admitted if they need reirradiation on the CNS). Suitability of reirradiation, especially in DIPG, should be discussed in a multidisciplinary setting. Reirradiation should be delivered with attention to minimising the risks of toxicity, harm and decreased quality of life in a child's final months. ${ }^{28}$

Although our study did not report the same primary outcome as more recent studies on paediatric patients and HI-EOL care, ${ }^{78}$ we can compare some individual measures of HI-EOL care.

We noted that the proportions of patients in the Ontario series ${ }^{8}$ given intravenous chemotherapy or radiotherapy during the last 2 weeks of life was very similar, while the percentage of cases receiving $\mathrm{HI}$ 
EOL care as a whole was lower in our series. The latter difference may relate to different, HI EOL criteria, ways in which palliative care is delivered, and heath care systems are organised. Our study also concerned a much shorter time interval and was more recent (2018-2020, as opposed to 2000-2012 for the Ontario series).

In the French study, ${ }^{7}$ HI-EOL care was provided more frequently (for $50 \%$ of patients vs $26 \%$ in our case), but their series only considered patients who died in hospital. It also included patients with leukaemias, and we know that they most frequently die in hospital due either to treatment-related complications or to the less predictable disease trajectories, compared with patients with solid tumours. ${ }^{2930}$ Revon-Rivière et al similarly reported that patients with CNS cancers, together with patients with haematological tumours, were more likely to receive more aggressive EOL treatments. ${ }^{7}$

An extremely different finding that emerged between our patient series and the aforementioned cohorts concerns patients' access to intensive care in the last month of their lives. In our sample, $7 \%$ of patients went into intensive care, while in the Canadian and French samples the proportions were $21 \%$ and $34 \%$, respectively. This is probably due, once again, to the presence of patients with haematological malignancies in other series, and perhaps to how ${ }^{78}$ heath care systems are organised.

Compared with our earlier report, ${ }^{14}$ it is worth noting that both the number of deaths at home and the proportion of patients given active palliative care had increased over time. As mentioned above, our previous data regarding the concurrent provision of palliative care during the course of a disease showed that patients given active palliative care from early on were at lower risk of experiencing HI-EOL care. ${ }^{10}$ Other groups have also reported similar findings. ${ }^{31}$ Research has shown that most parents and clinicians prefer a paediatric patient's EOL care and death to be managed at home, ${ }^{32} 33$ and this is more likely to happen when a palliative care team is involved. ${ }^{34}$ That said, families are all different, each with their own problems and needs, and home may not always be the ideal place for a terminal patient. Place of residence can also strongly affect the therapeutic strategies adopted and the EOL care available, partly because access to palliative care is by no means homogeneous in Italy. ${ }^{23}$

Patients with cancer sometimes receive treatments up until their death. This may be at the request of the patients themselves or their families, or because their oncologists struggle with the idea of recommending no further treatment to avoid depriving parents of their last hopes. ${ }^{35}$ Such requests for, or offers of further treatments can sometimes be a source of conflict with palliative care teams, who may judge it better to give the family a clear message regarding their child's prognosis and help them to come to terms with it. On the other hand, oncological treatments that can be administered at home, without any excessive toxicity or the need for hospitalisation, may help to sustain a family's hopes ${ }^{36}$ without interfering with the daily activities of the patients and their families.

There is also the matter of the phase I/II trials that some centres (like ours) are accredited to conduct, and a patient's involvement necessarily entails frequent visits to the hospital. Participation in phase I trials does not seem to affect the characteristics of EOL care for paediatric oncology patients, ${ }^{37}$ but this is only true if palliative care consultations are a routine part of the process for enrolling patients in phase I trials. ${ }^{38}$

Another issue to consider is the risk of concentrating too much on treatments, or on managing organic symptoms, and not enough on a patient's emotional-existential and spiritual well-being. Even on the subject of planning for the EOL, the more or less explicit wishes of the child/ adolescent, and a 'possible heritage' may risk going overlooked. Research has shown that having a proper conversation regarding the aspects involved in the EOL helps families to prepare for the time of death, and even to cope better with their bereavement. ${ }^{39}$

Limitations: Several limitation of this study should be considered: the sample size is small, as it is a monoinstitutional work, so it does not reflect the real situation in our country. For the statistical analysis, we have a lack of a multivariate analysis. We did not capture the preference of the families and the patients about the preference of dying at home, in paediatric oncology unit or the hospital near home. It is not obvious the preferred place for EOL. We missed some data about EOL, some patients living in the south of Italy were cured in the terminal phase by other hospital and we could not have all data.

\section{CONCLUSIONS}

Our results highlight the importance of weighing up the pros and cons of specific treatments and their intensity at the EOL, especially when families and patients have expressed the wish to spend the terminal phase at home, since we found that to prescribe intensive rescue oncological treatment during the EOL period correlates with an higher probability of dying far from home. Whenever possible, the proposed treatments should balance the chances of improving the patient's condition with those of offering the best quality of life by providing the best supportive care.

The early activation of palliative care, especially in such fragile and complicated patients as those with CNS cancers, could help families to cope with the many problems they encounter.

Acknowledgements The authors wish to thank the Associazione Bianca Garavaglia Onlus, Busto Arsizio (VA).

Contributors MGP, ES, VB and GG have contributed to the conception or design of the study; MGP, NP, LB, ON and MC have contributed to data collection; MGP, MM and CAC have contributed to the data analysis; MGP, RL, FS and MT have contributed to data interpretation; MGP drafted the 
manuscript; MGP, SC, MC and AF were involved in critical revision of the manuscript. All authors gave their final approval of the version to be published.

Funding The authors have not declared a specific grant for this research from any funding agency in the public, commercial or not-for-profit sectors.

Competing interests None declared.

Patient consent for publication Not required.

Ethics approval The study was conducted in Italy and approved by the ethics committee of CEI Fondazione IRCCS Fondazione Istituto Tumori of Milan (approval number N. INT 79/21).

Provenance and peer review Not commissioned; externally peer reviewed.

Data availability statement Data are available in a public, open access repository. Data are available only with authorisation by ethical commettee.

\section{ORCID iD}

Marta Giorgia Podda http://orcid.org/0000-0002-0855-2526

\section{REFERENCES}

1 I Tumori in Italia, rapporto AIRTUM 2012, tumori INFANTILI. Epidemiol Prev 2013;37:1-296.

2 Fischer C, Petriccione M, Donzelli M, et al. Improving care in pediatric neuro-oncology patients: an overview of the unique needs of children with brain tumors. J Child Neurol 2016;31:488-505.

3 Mack JW, Joffe S, Hilden JM, et al. Parents' views of cancerdirected therapy for children with no realistic chance for cure. J Clin Oncol 2008;26:4759-64.

4 Park JD, Kang HJ, Kim YA, et al. Trends in the aggressiveness of end-of-life care for Korean pediatric cancer patients who died in 2007-2010. PLoS One 2014;9:e99888.

5 Cohen-Gogo S, Marioni G, Laurent S, et al. End of life care in adolescents and young adults with cancer: experience of the adolescent unit of the Institut Gustave Roussy. Eur J Cancer 2011;47:2735-41.

6 Kaye EC, Gushue CA, DeMarsh S, et al. Illness and end-of-life experiences of children with cancer who receive palliative care. Pediatr Blood Cancer 2018;65:e26895.

7 Revon-Rivière G, Pauly V, Baumstarck K, et al. High-intensity end-of-life care among children, adolescents, and young adults with cancer who die in the hospital: a population-based study from the French national hospital database. Cancer $2019 ; 125: 2300-8$.

8 Salins N, Ghoshal A, Hughes S, et al. How views of oncologists and haematologists impacts palliative care referral: a systematic review. BMC Palliat Care 2020;19:175.

9 Mack JW, Wolfe J. Early integration of pediatric palliative care: for some children, palliative care starts at diagnosis. Curr Opin Pediatr 2006;18:10-14.

10 Podda M, Schiavello E, Visconti G, et al. Customised pediatric palliative care: integrating oncological and palliative care priorities. Acta Paediatr 2021;110:682-8.

11 Earle CC, Landrum MB, Souza JM, et al. Aggressiveness of cancer care near the end of life: is it a quality-of-care issue? J Clin Oncol 2008;26:3860-6.

12 Kassam A, Sutradhar R, Widger K, et al. Predictors of and trends in high-intensity end-of-life care among children with cancer: a population-based study using health services data. $J$ Clin Oncol 2017;35:236-42.

13 Tzuh Tang S, Hung Y-N, Liu T-W, et al. Pediatric end-of-life care for Taiwanese children who died as a result of cancer from 2001 through 2006. J Clin Oncol 2011;29:890-4.

14 Beretta S, Polastri D, Clerici CA, et al. End of life in children with cancer: experience at the pediatric oncology department of the Istituto nazionale Tumori in Milan. Pediatr Blood Cancer 2010;54:88-91.

15 Kuhlen M, Hoell J, Balzer S, et al. Symptoms and management of pediatric patients with incurable brain tumors in palliative home care. Eur J Paediatr Neurol 2016;20:261-9.

16 Veldhuijzen van Zanten SEM, van Meerwijk CLLI, Jansen MHA, et al. Palliative and end-of-life care for children with diffuse intrinsic pontine glioma: results from a london cohort study and international survey. Neuro Oncol 2016;18:582-8.

17 Blais S, Cohen-Gogo S, Gouache E, et al. End-of-life care in children and adolescents with cancer: perspectives from a French pediatric oncology care network. Tumori 2021:030089162110133.

18 Petit A, Aerts I, Lobut J. End-Of-Life in pediatric hematooncology. MT Pediatr 2009;12:127-33.

19 Cohen-Gogo S, Marioni G, Laurent S, et al. End of life care in adolescents and young adults with cancer: experience of the adolescent unit of the institut gustave roussy. Eur J Cancer 2011;47:2735-41.

20 Bertrand A, Marcault-Derouard A, Devaux Y, et al. Soins palliatifs pédiatriques et fin de vie d'enfants suivis en oncohématologie: place de l'hospitalisation à domicile. Bull Cancer 2018;105:771-9.

21 Gao W, Verne J, Peacock J, et al. Place of death in children and young people with cancer and implications for end of life care: a population-based study in England, 1993-2014. BMC Cancer 2016;16:727.

22 Kaye EC, Gushue CA, DeMarsh S, et al. Illness and end-of-life experiences of children with cancer who receive palliative care. Pediatr Blood Cancer 2018;65. doi:10.1002/pbc.26895. [Epub ahead of print: 0812 2017].

23 ISTAT [Italian Institute of Statistics]. Italian ministry of public health and Commission on pediatric palliative care, 2006.

24 Benini F, Ferrante A, Buzzone S. Childhood deaths in Italy. EJPC 2008;15:77-81.

25 Ministero della Salute e Commissione. Cure palliative pediatriche, documento tecnico: cure palliative rivolte al neonato, bambino e Adolescente, 2007.

26 Janssens GO, Gandola L, Bolle S, et al. Survival benefit for patients with diffuse intrinsic pontine glioma (DIPG) undergoing re-irradiation at first progression: a matchedcohort analysis on behalf of the SIOP-E-HGG/DIPG working group. Eur J Cancer 2017;73:38-47.

27 Tsang DS, Laperriere NJ. Re-irradiation for paediatric tumours. Clin Oncol 2019;31:191-8.

28 Ermoian R, MacDonald S, Laack NNI, et al. Reirradiation in pediatric patients with recurrent brain tumors: a last hope, but one with greatly feared consequences. Int J Radiat Oncol Biol Phys 2019;103:1-4.

29 Oechsle K. Palliative care in patients with hematological malignancies. Oncol Res Treat 2019;42:25-30.

30 Verhoef M-J, de Nijs EJM, Ootjers CS, et al. End-of-life trajectories of patients with hematological malignancies and patients with advanced solid tumors visiting the emergency department: the need for a proactive integrated care approach. Am J Hosp Palliat Care 2020;37:692-700.

31 Widger K, Sutradhar R, Rapoport A, et al. Predictors of specialized pediatric palliative care involvement and impact on patterns of end-of-life care in children with cancer. J Clin Oncol 2018;36:801-7.

32 Kassam A, Skiadaresis J, Alexander S, et al. Parent and clinician preferences for location of end-of-life care: home, hospital or freestanding hospice? Pediatr Blood Cancer 2014;61:859-64.

33 Bluebond-Langner M, Beecham E, Candy B, et al. Preferred place of death for children and young people with life-limiting and life-threatening conditions: a systematic review of the literature and recommendations for future inquiry and policy. Palliat Med 2013;27:705-13. 
34 Wolfe J, Hammel JF, Edwards KE, et al. Easing of suffering in children with cancer at the end of life: is care changing? JCO 2008;26:1717-23.

35 Figueroa Gray M, Ludman EJ, Beatty T, et al. Balancing hope and risk among adolescent and young adult cancer patients with late-stage cancer: a qualitative interview study. J Adolesc Young Adult Oncol 2018;7:673-80.

36 Tomlinson D, Bartels U, Gammon J, et al. Chemotherapy versus supportive care alone in pediatric palliative care for cancer: comparing the preferences of parents and health care professionals. CMAJ 2011;183:E1252-8.
37 Levine DR, Johnson L-M, Mandrell BN, et al. Does phase 1 trial enrollment preclude quality end-of-life care? Phase 1 trial enrollment and end-of-life care characteristics in children with cancer. Cancer 2015;121:1508-12.

38 Lord S, Weingarten K, Rapoport A. Palliative care consultation should be routine for all children who enroll in a phase I trial. JCO 2018;36:1062-3.

39 Mack JW, Weeks JC, Wright AA, et al. End-of-life discussions, goal attainment, and distress at the end of life: predictors and outcomes of receipt of care consistent with preferences. J Clin Oncol 2010;28:1203-8. 